\title{
The Analysis of Neurologic Manifestations with Major Electrolyte Abnormalities
}

\author{
Shirisha Chinthoju ${ }^{1}$, Radhika Kancha', Sindgi Vasudeva Murthy ${ }^{2}$, MadhuBabu $\mathbf{S}^{3}$, \\ Thungathurthi Smitha ${ }^{1, *}$
}

1Department of Pharmacy Practice, Jayamukhi College of Pharmacy, Affiliated to Kakatiya University Narsampet, Warangal (R), Telangana, INDIA

${ }^{2}$ Department of Pharmacology, Jayamukhi College of Pharmacy, Affiliated to Kakatiya University, Narsampet,

Warangal (R), Telangana, INDIA

${ }^{3}$ Madhubabu Neuro and Multispeciality Center, Hanamakonda. Warangal (U), Telangana, INDIA

\begin{abstract}
Background: Neurologic manifestations caused by the major electrolyte abnormalities in neurologic conditions. The clinical significance of electrolytes in clinical practice and their abnormalities are developing in any of the neurological manifestations and along with other complications. Objectives: The neurological manifestation requires effective management of the electrolyte disorder, which are primarily reversible. In this study we examined electrolyte imbalances that are threatening the life and examined the existent symptoms in neurological patients. Materials and Methods: In this prospective study subjects satisfying the inclusion criteria were enrolled and examined for their neurologic manifestations and analyzed different electrolytes levels. Patients' demographics, electrolyte investigations, diagnosis and details of neurologic symptoms were noted. Electrolyte levels in various neurologic diseases were compared and correlations between the electrolyte abnormalities and neurologic manifestations made to identify the electrolyte imbalances and preceding symptoms. Results: For this study subjects with symptoms along with pertinent neurological diseases enrolled. A total of 218 patients, of them 161 patients found with electrolyte abnormalities. This study included the patients diagnosed with various neurologic diseases such as spondylosis (66.5\%), Migraine (13.7\%), Head injury $(5.5 \%)$, Stroke $(5 \%)$ and seizures $(1.37 \%)$ and other conditions $(7.79 \%)$. The patients' electrolytes data revealed significant changes in sodium, potassium and calcium electrolyte anomalies resulting in neurologic manifestations. Conclusion: We infer that patients with disturbances in various electrolytes are at high risk for the development of various manifestations. Appropriate recognition, monitoring and management should be done to minimize the effects of the neurological complications.
\end{abstract}

Key words: Sodium, Potassium, Calcium, Electrolyte abnormalities, Neurologic manifestations.

\section{INTRODUCTION}

Central and peripheral neurologic manifestations are associated with electrolyte disturbances which are frequently observed in clinical practice. The electrolytes disorganization in different neurological condition is primarily functional than structural. Prompt management of electrolyte imbalances in early stages reverses such neurologic manifestations. ${ }^{1,2} \mathrm{~A}$ proper functioning of nervous system requires appropriate distribution of electrolytes in its related compartments. Neurologic manifestations may occur when there is a disturbance in the distribution and concentration of these gradients. Seizures may results due to altered level of phosphate, sodium and calcium. Imbalances in magnesium, calcium and phosphate may be a reason for the changes in sensorium. ${ }^{3,4}$

Several symptoms like headache, vomiting, nausea, gait disturbances, dizziness, mild dementia, irritability, involuntary muscle contractions common among mild hyponatremeia. ${ }^{5-7}$ The earliest clinical symptoms such as nausea and malaise may be observed at $125-130 \mathrm{mEq} / \mathrm{L}$ of sodium levels and further decline to $115-120 \mathrm{mEq} / \mathrm{L}$ may lead to convulsions, unconsciousness and respiratory collapse may occur. ${ }^{7,8}$ Patients with tumors, stroke, inflammation or any other intracranial disease may be
DOI: 10.5530/ijopp.13.2.24

Address for correspondence: Thungathurthi Smitha Department of Pharmacy Practice, Jayamukhi College of Pharmacy, Affiliated to Kakatiya University Narsampet - 503332 Warangal (R), Telangana, INDIA. Phone no: +919618692542 Email Id: smithakatyan@gmail. com

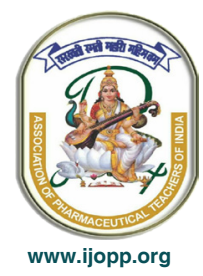


sensitive to sudden fall in sodium levels that may advance to coma. ${ }^{7,9}$ Hypernatremia may results from insufficient $\mathrm{ADH}$ release and inadequate water intake., ${ }^{410}$

Potassium imbalances rarely involve the Central Nervous System (CNS) and are predominantly associated with muscle symptoms. Of total electrolytes, intracellular potassium accounts for $60 \%$ and is located in the muscles, hence the disturbances in their distribution may result in muscle symptoms. In clinical practice, the most frequent electrolyte imbalance observed is hypokalemia which may be due to insufficient potassium consumption or due to unwarranted renal or gastrointestinal loss. The symptoms like myalgia, muscle weakness and alleviation of the fatigue reported with 3.0 to $3.5 \mathrm{mEq} / \mathrm{L}$ of Potassium. Further decline in potassium concentration 2.5 to $3.0 \mathrm{mEq} / \mathrm{L}$ may result in muscle weakness along with muscle cramps. Rhabdomyolysis and myoglobinuria (structural muscle damage) may be observed while serum potassium concentration decrease below 2.5 or 2.0 $\mathrm{mEq} / \mathrm{L}$. Hypokalemic cerebral symptoms may be mild and rare. Mild muscle weakness is the mostly observed manifestation of hyperkalemia and often observed in chronic adrenal deficiency. ${ }^{1,11,12}$

Excitable membranes of muscle and nervous tissues are stabilized by serum calcium. Thus the calcium disorders may result in neurologic manifestations. ${ }^{1,13}$ Hypocalcemia may results in neurological symptoms like seizures and alternations of the mental status. The manifestation of other diseases includes mental disturbances, neurosis, delusion, delirium, mental clouding, dementia and retardation of the mental activity. In case of chronic hypocalcemia, chorea and Parkinsonism may be observed. The majority observed indication of hypocalcemia is tetany ${ }^{14}$ whereas in a few cases hypocalcemia leads to the generalized or focal seizures. ${ }^{15}$

\section{MATERIALS AND METHODS}

A prospective study was conducted in a secondary care hospital for a period of 6 months between December 2018 to May 2019. The study intended to analyze neurologic manifestations of electrolyte abnormalities in patients with various neurologic diseases.

Patients attending to the neurology clinic were screened based on their electrolytes abnormalities and observed for their neurologic manifestations. The required data was collected in a specially prepared data collection form, which includes patient demographics, electrolyte investigations, diagnosis and details of neurological symptoms. Patients with an underlying neurological condition are also included in the present study.
Hypotensive, renal impairment, diarrheal patients and other co-morbid patients were also included.

Patients' data with various neurologic manifestations along with major electrolyte imbalances such as sodium, potassium, calcium analyzed. Clinical chemistry analyzer 'CPC Stat Fax 3000-Plus' was used to determine electrolyte levels. The study design, appropriateness and objectives of the study approved by the Institutional Review Board (JCP/IRB/2019/05). Informed consent was taken from the subjects enrolled during the study.

Data was analyzed using the trial versions of GraphPad Prism 8.2.0 and Med Calc software package. Tukey's multiple comparison test carried out after one-way ANOVA performed. Logistic regression test was used to analyze the relation between the electrolyte abnormalities and symptoms. $P$ value less than 0.05 was considered as significant.

\section{RESULTS}

A total 218 patients examined for their neurologic manifestations along with quantitative analysis of the electrolytes. Among 218 patients, the electrolyte abnormalities were reported in $161(73.8 \%)$ and remaining $57(26.2 \%)$ subjects with normal levels of electrolytes. Neurologic manifestations were observed in 115 patients while 46 subjects found to be asymptomatic. The patients' demographic data, details of various neurologic diseases and the electrolyte levels of the subjects participated mentioned in Table 1-3.

\section{Table 1: Demographic data of the subjects}

\section{participated.}

\begin{tabular}{|c|c|c|c|}
\hline & Male, $\mathrm{n}(\%)$ & $\begin{array}{c}\text { Female, } \\
\text { n (\%) }\end{array}$ & Total (\%) \\
\hline Gender & 74(33.90) & $\begin{array}{c}144 \\
(66.10)\end{array}$ & 218 \\
\hline \multicolumn{4}{|c|}{ Age } \\
\hline $\begin{array}{c}\text { 13-19 Age } \\
\text { Group }\end{array}$ & $3(1.40)$ & $4(1.80)$ & $7(3.3)$ \\
\hline $\begin{array}{l}20-40 \text { Age } \\
\text { Group }\end{array}$ & $29(27.8)$ & $28(26.9)$ & $104(64.2)$ \\
\hline $\begin{array}{l}\text { 41-60 Age } \\
\text { Group }\end{array}$ & $27(33.70)$ & $53(66.2)$ & $80(36.6)$ \\
\hline$>60$ Age & $07(7.70)$ & $20(9.10)$ & $27(16.9)$ \\
\hline \multicolumn{4}{|c|}{ Locality } \\
\hline $\begin{array}{c}\text { Rural } \\
\text { Background }\end{array}$ & $63(28.80)$ & $\begin{array}{c}128 \\
(58.70)\end{array}$ & 191(87.7) \\
\hline $\begin{array}{c}\text { Urban } \\
\text { Background }\end{array}$ & $11(5)$ & $16(7.30)$ & $27(12.3)$ \\
\hline \multicolumn{4}{|c|}{ Type of life style } \\
\hline $\begin{array}{c}\text { Sedentary Life } \\
\text { Style }\end{array}$ & $10(4.5 \%)$ & $18(8.2 \%)$ & $28(13.9)$ \\
\hline $\begin{array}{c}\text { Non sedentary } \\
\text { Life Style }\end{array}$ & $134(61.4 \%)$ & $\begin{array}{c}56 \\
(25.6 \%)\end{array}$ & 190(87.1) \\
\hline
\end{tabular}


Table 2: Electrolyte imbalances in various neurologic diseases among patients.

\begin{tabular}{ccc}
$\begin{array}{c}\text { Medical } \\
\text { Conditions }\end{array}$ & Total $\mathbf{n}(\%)$ & $\begin{array}{c}\text { Electrolyte imbalance, } \\
\mathbf{n}(\%)\end{array}$ \\
\hline Spondylosis & $145(66.5)$ & $107(73.7)$ \\
Migraine & $30(13.7)$ & $26(86.6)$ \\
Head injury & $12(5.5)$ & $8(66.6)$ \\
Stroke & $11(5)$ & $4(36.6)$ \\
Seizures & $3(1.37)$ & $3(100)$ \\
Others & $17(7.79)$ & $13(76.4)$ \\
\hline
\end{tabular}

\begin{tabular}{|c|c|c|c|}
\hline Electrolytes & $\begin{array}{l}\text { Male, } n \\
(\%)\end{array}$ & $\begin{array}{c}\text { Female, } \mathbf{n} \\
(\%)\end{array}$ & Total (\%) \\
\hline \multicolumn{4}{|c|}{ Sodium } \\
\hline $\begin{array}{c}\text { Normal } \\
(135-145 \mathrm{mEq} / \mathrm{L})\end{array}$ & $42(19.7 \%)$ & $109(50 \%)$ & $151(69.7 \%)$ \\
\hline $\begin{array}{c}\text { Hyponatremia } \\
\text { (<135mEq/L) }\end{array}$ & $1(0.4 \%)$ & $3(1.3 \%)$ & $4(1.8 \%)$ \\
\hline $\begin{array}{l}\text { Hypernatremia } \\
(<145 \mathrm{mEq} / \mathrm{L})\end{array}$ & $30(13.7 \%)$ & $31(14.2 \%)$ & $61(27.9 \%)$ \\
\hline \multicolumn{4}{|c|}{ Potassium } \\
\hline $\begin{array}{c}\text { Normal } \\
(3.5-4.5 \mathrm{mEq} / \mathrm{L})\end{array}$ & $59(27 \%)$ & $105(48.2 \%)$ & $164(75.2 \%)$ \\
\hline $\begin{array}{l}\text { Hypokalemia } \\
(<3.5 \mathrm{mEq} / \mathrm{L})\end{array}$ & $10(4.5 \%)$ & $35(16.1 \%)$ & $45(20.6 \%)$ \\
\hline $\begin{array}{l}\text { Hyperkalemia } \\
(>4.5 \mathrm{mEq} / \mathrm{L})\end{array}$ & $4(1.8 \%)$ & $3(1.3 \%)$ & $7(3.2 \%)$ \\
\hline \multicolumn{4}{|c|}{ Calcium } \\
\hline $\begin{array}{c}\text { Normal } \\
(8.8-10.2 \mathrm{mg} / \mathrm{dL})\end{array}$ & $35(16.1 \%)$ & $46(21 \%)$ & $79(36.2 \%)$ \\
\hline $\begin{array}{l}\text { Hypocalcemia } \\
(<8.8 \mathrm{mg} / \mathrm{dL})\end{array}$ & $24(11.0 \%)$ & $80(36.7 \%)$ & 107 (49\%) \\
\hline $\begin{array}{l}\text { Hypercalcemia } \\
(>10.2 \mathrm{mg} / \mathrm{dL})\end{array}$ & 0 & 0 & 0 \\
\hline
\end{tabular}

Multiple Logistic Regression was used to determine the relation between in symptoms and electrolyte imbalances. The Significance indicates that electrolyte abnormalities will result in neurologic manifestations. $* * *$ indicates statistically highly significant

Electrolyte abnormality and clinical manifestations: The symptoms caused by major electrolyte abnormalities with sodium, potassium and calcium were referred and the patients reporting the experiences of the symptoms noted.

According to the experimental studies, sodium less than normal level may not result in any neurologic manifestations. Majority of the patients in this study didn't experience the neurologic manifestations but very few patients complained with tremors and rigidity. Patients with more than normal sodium levels revealed the symptoms of rigidity, tremors and asterixis. The overall changes in electrolyte imbalances confirm the significant relationship with the neurologic manifestations. The relation between the symptoms and potassium abnormalities were analyzed. Patients with less potassium level exhibited muscle weakness, ease of fatigue and hyperkalemic patients with muscle weakness. Hypocalcemia resulted in neurologic manifestations such as irritability, anxiety, confusion, depression and dementia (Table 4).

\section{Electrolytes correlation in various neurologic conditions}

Comparison of calcium, sodium and potassium levels of the patients in various neurological conditions made by with one way ANOVA followed by multiple comparison tests by Tukey's analysis. Various neurologic disorders like stroke, migraine, spondylosis, head injury and other conditions such as weakness, DVT and arthritis included in the study. The results prove that there is no relation between for the above mentioned neurologic disorders and electrolyte abnormality.

Low calcium levels established in migraine and spondylosis and normal levels of calcium in head injury and stroke. Low calcium levels observed in conditions such as arthritis, Deep Vein Thrombosis (DVT), generalized weakness and psychosis. In the current normal sodium level confirmed in different neurological patients along with potassium levels, while the calcium levels were found to be low in all neurologic conditions except stroke (Table 5).

\section{DISCUSSION}

This study analyzed the patients' various neurologic manifestations and electrolytes abnormalities. Various neurologic manifestations like headache, confusion, muscle cramps, lethargy, irritability and obtundation observed in patients with hyponatremeia. ${ }^{1,4}$ Similarly in the current study the most common symptoms observed were confusion, hemiparesis, ataxia, tremors and rigidity and it corroborates with previous studies. Study revealed that the manifestations of hypernatremia include rigidity, tremors, asterixis, myoclonus, altered sensorium and coma. ${ }^{4}$ Resemblance to previous study noticed in patients with hypernatremia indicated with conditions namely rigidity, tremors, asterixis, myoclonus and chorea. 
Table 4: The relationship between symptoms and electrolyte imbalances.

\begin{tabular}{cccc} 
Variable & Wald test & $\boldsymbol{P}$ values & $\begin{array}{c}\text { Significance } \\
\text { level }\end{array}$ \\
\hline Hypocalcemia & 23.8181 & $<0.0001$ & $* * *$ \\
Hyponatremia & 3.0227 & 0.0821 & $\mathrm{~ns}$ \\
Hypernatremia & 25.841 & $<0.0001$ & $* * *$ \\
Hypokalemia & 50.9234 & $<0.0001$ & $* * *$ \\
Hyperkalemia & 8.4888 & 0.0036 & $* * *$ \\
\hline
\end{tabular}

Table 5: Electrolyte levels in subjects with various neurologic disorders.

\begin{tabular}{cc} 
Calcium & Mean (SD) \\
\hline Migraine & $8.42(0.60)$ \\
Spondylosis & $8.46(0.60)$ \\
Head injury & $8.80(0.44)$ \\
Stroke & $8.93(0.34)$ \\
Others & $8.43(0.54)$ \\
Sodium & \\
Migraine & $143.8(3.73)$ \\
Spondylosis & $143.3(4.96)$ \\
Head injury & $142.0(2.76)$ \\
Stroke & $143.0(2.82)$ \\
Others & $142.3(5.93)$ \\
Potassium & \\
Migraine & $3.86(0.45)$ \\
Spondylosis & $3.89(0.41)$ \\
Head injury & $3.65(0.30)$ \\
Stroke & $3.67(0.37)$ \\
Others & $3.73(0.411)$ \\
\hline
\end{tabular}

Muscle weakness manifested in hyperkalemic patient. ${ }^{1}$ Similar findings observed in patients with hyperkalemia in the present study. The clinical advancement of muscle weakness involving the proximal limb muscle along with the muscle cramps noticed in patients with low levels of potassium. Manifestations like rhabdomyolysis, myoglobinuria, confusion and irritability observed in few individuals with low potassium level ${ }^{1}$ and current findings corroborated with this study.

In the present study in most of the patients hypocalcemia was observed than other electrolytes. The neurologic manifestations resulted in conditions like irritability, anxiety, depression, confusion and dementia like symptoms observed like previous studies. ${ }^{1}$ In overall study, patients with hypercalcemia condition was not observed.

\section{CONCLUSION}

The study revealed electrolyte abnormalities resulted in neurological manifestations. Regular monitoring of electrolytes in out-patient might help in early detection of manifestations related to electrolytes abnormalities and reduces the risk of development of the diseases.

\section{ACKNOWLEDGEMENT}

We thank Dr. Madhu Babu and the staff of Madhu Babu Neuro Clinic, Hanamakonda, Telangana for the clinical and technical support.

\section{CONFLICT OF INTEREST}

The authors declare no conflict of interest.

\section{ABBREVIATIONS}

CNS: Central Nervous System; MEq/L: Milli equivalents/Liter; ADH: Anti Diuretic Hormone; ANOVA: Analysis of Variance; DVT: Deep Vein Thrombosis; SD: Standard Deviation.

\section{REFERENCES}

1. Riggs J. Neurologic Manifestations of Electrolyte Disturbances. Neurol Clin. 2014;20(1):317-26.

2. Riggs J. Neurologic Manifestations of Electrolyte Abnormalities. Neurol Clin. 2002;20(1):227-39

3. Diringer M, Zazulia A. Hyponatremia in neurologic patients. The Neurologist. 2006;12(3):117-26.

4. Diringer M. Handbook of Clinical Neurology, (3rd series) Critical Care Neurology, Part II, Washington University, St. Louis, MO, USA. 2017;141:70513.

5. Sterns R, Cappuccio J, Silver S. Neurologic sequelae after treatment of severe hyponatremia: A multicenter perspective. J Am Soc Nephrol.1994;4(8):1522-30.

6. Sterns R, Riggs J, Schochet S. Osmotic demyelination syndrome following Correction of hyponatremia. N Eng J Med. 1986;314(24):1535-42.

7. Sterns R. Disorders of plasma sodium - causes, consequences and correction. N Eng J Med. 2015;372(1):55-65.

8. Ellis S. Severe hyponatraemia: Complications and treatment. QJM: Interna J Med. 1995;88(12):905-9.

9. Ayus J. Postoperative hyponatremic encephalopathy in menstruant women. Ann Intern Med. 1992;117(11):891-7.

10. Singhal P, Abramovici M, Venkatesan J. Hypokalemia and rhabdomyolysis. Miner Electrolyte Metab. 1991;17(5):335-9.

11. Melton J, Patlak $\mathrm{C}$, Pettigrew $\mathrm{K}, \mathrm{Cserr} \mathrm{H}$. Volume regulatory loss of $\mathrm{Na}, \mathrm{Cl}$ and $\mathrm{K}$ from rat brain during acute hyponatremia. Am J Physiol. 1987;252(4):F6619.

12. Freeman S, Fale A. Muscular paralysis and ventilatory failure caused by hyperkalaemia. Br J Anaesth. 1993;70(2):226-7.

13. Cheek J, Riggs J, Lilly R. Extensive brain calcification and progressive dysarthria and dysphagia associated with chronic hypoparathyroidism. Arch Neurol. 1990;47(9):1038-9.

14. Banebe J, Martinez MM. Disorder of fluid electrolyte metabolism. 5th ed. New York. 1994.

15. Tohme J, Bilezikian J. Hypocalcemic Emergencies. Endocrinol Metab Clin North Am. 1993; 22(2):363-75. 